\title{
SOCIEDADE E CONSUMO: UMA ANÁLISE SOBRE AS RELAÇÕES DE CONSUMO E O PROCESSO DE SUBJETIVAÇÃO NA MODERNIDADE
}

\author{
SOCIEDAD Y CONSUMO: UN ANALISIS SOBRE LAS RELACIONES DE CONSUMO \\ Y EL PROCESO DE SUBJETIVACIÓN EN LA MODERNIDAD
}

SOCIETY AND CONSUMPTION: AN ANALYSIS OF CONSUMER RELATIONS AND THE PROCESS OF SUBJECTIFICATION IN MODERNITY

\author{
Remo dos SANTOS ${ }^{1}$ \\ Pedro Augusto Dinelli CRUZ ${ }^{2}$
}

RESUMO: Este estudo buscará, por meio de pesquisa bibliográfica, um estudo sobre o processo de subjetivação na Sociedade de Consumo. Para isso, recorrerá a escritos de teóricos como Michel Foucault para uma análise da estrutura das sociedades ao longo da história, o que reforçará uma afirmação do tipo de comportamento de cada sociedade. Esse ponto se faz importante para determinar o que é a cultura do consumo nessa sociedade. O consumo se mostrará aqui para além do próprio ato de consumir, criando lógicas e comportamentos, demonstrando que para a sociedade de consumo, o exercício de possuir fica em segundo plano, quando é a própria busca pelo desejo de consumir que mantém a roda do consumo girando. O consumo aqui é central e o sujeito se mostrará como agente do consumo, sendo impulsionado e transformado pelo mesmo.

PALAVRAS-CHAVE: Subjetividade. Sociedade. Consumo.

RESUMEN: Este estudio buscará, a través de la investigación bibliográfica, un estudio sobre el proceso de subjetivación en la Sociedad de Consumo. Para ello, recurrirá a los escritos de teóricos como Michel Foucault para un análisis de la estructura de las sociedades a lo largo de la historia, que reforzará una afirmación del tipo de comportamiento de cada sociedad. Este punto es importante para determinar cuál es la cultura de consumo en esta sociedad. El consumo se mostrará aquí más allá del acto real de consumir, creando lógicas y comportamientos, demostrando que para la sociedad de consumo, el ejercicio de la propiedad está en segundo plano, cuando es la búsqueda del deseo por consumir lo que mantiene el consumo funcionando. El consumo aqui es central y el sujeto se mostrará como un agente de consumo, siendo impulsado y transformado por él.

PALABRAS CLAVE: Subjetividad. Sociedad. Consumo.

${ }^{1}$ Centro Universitário de Barra Mansa (UBM), Barra Mansa - RJ - Brasil. Graduado no curso de Psicologia. ORCID: https://orcid.org/0000-0002-0143-0534. E-mail: santos.remo@gmail.com

${ }^{2}$ Universidade Estácio de Sá (UNESA), Rio de Janeiro - RJ - Brasil. Docente do curso de Psicologia - UBM. Mestrado em Ciências Sociais (UFRRJ). ORCID: https://orcid.org/0000-0002-9523-9713. E-mail: pdcruz88@gmail.com 
ABSTRACT: This study will search through bibliographic research a study about the subjectification process in the Consumer Society. This will require the use of writings by theorists such as Michel Foucault for an analysis of the structure of societies throughout history, which will reinforce a statemant of the type of behavior of each society. This is an importante point to determine what is the consumer culture in this society. Consumption will be shown here beyond the actual act of consuming, creating logic and behaviors, demonstrating that for the consumer society, the exercise of owning is in the background, when it is the very persuit of the desire to consume that keeps the consumption wheel spinning. Consumption here is central and the subject will show itself as an agent of consumption, being driven and transformed by it.

KEYWORDS: Subjectivity. Society. Consumption.

\section{Introdução}

As sociedades passam por processos de mudanças, ao longo da história, e, em cada uma delas, podemos identificar práticas que as caracterizam. Essas práticas estão no campo do imaginário social e podem ser identificadas através de estudos de competência das ciências sociais e históricas. Quando se observa uma sociedade com cuidado pode-se identificar nela traços que são sempre repassados das anteriores para as mais atuais. Este artigo pretende analisar algumas delas com foco principal na Sociedade de Consumo

Partindo de um processo histórico, através de pesquisas bibliográficas, mostraremos como são manifestas e como se organizam as relações sociais. Afinal, quais práticas sociais diferenciam outras sociedades da sociedade de consumo? A resposta para essa pergunta é objetivo principal desse artigo.

$\mathrm{Na}$ Sociedade de Consumo, procuraremos demonstrar como acontecem as relações, das quais, Bauman (2008) vai chamar a atenção para a obsolescência e liquidez. Veremos que o mercado consumista investe tecnologia e tempo para formar agentes consumidores e que dentro dessa lógica, tudo é consumido, e consumir se torna um direito e um dever do sujeito dessa sociedade.

Há para isso uma formação, uma estrutura institucionalizada que promove a lógica do consumo e dá amparo para tais práticas. O homem nessa sociedade é ele próprio "comodificado", como alerta Bauman (2008).

Interessa-nos, então, observar quais tipos de agenciamentos ou de capturas são feitos nesse processo de consumir que potencializam tais práticas. Para isso, tentaremos apontar a questão dos agenciamentos dos fluxos de desejo, por meio da releitura de Deleuze e Guattari 
que mostram um desejo ligado ao campo social e político e que muito traz sentido para esse artigo.

Ao final do artigo, tentaremos evidenciar todas essas questões que dizem respeito às práticas atuais da sociedade moderna.

\section{Sociedades, instituições e práticas}

Iniciaremos nosso diálogo trazendo o significado do que é uma sociedade e de como é formada, por meio dos escritos de Baremblitt (2002) que afirma que "sociedade" é uma forma organizada de associação humana, com regras e costumes, também podendo ser chamadas de cultura ou práticas, e são formadas por “[...] uma rede, um tecido de instituições" (BAREMBLITT, 2002). Ainda segundo o autor, as instituições dizem respeito, então, às práticas e lógicas humanas, que dependendo do grau de formalização podem se tornar leis, mas que não se limitam apenas a formalização, podendo também serem informais e entendidas como hábitos culturais, mas que sempre dizem respeito à organização humana num contexto social.

O que essas lógicas significam? Significam a regulação de uma atividade humana, caracterizam uma atividade humana $\mathrm{e}$ se pronunciam valorativamente com respeito a ela esclarecendo o que deve ser, o que está prescrito, e o que não deve ser, isto é, o que está proscrito, assim como o que é indiferente. Essas lógicas, esses corpos discriminativos, são vários [...] (BAREMBLITT, 2002).

Ainda segundo (BAREMBLITT, 2002): "Em um plano formal, uma sociedade não é mais que isso: um tecido de instituições que se interpenetram e se articulam entre si para regular a produção e a reprodução da vida humana sobre a terra e a relação entre os homens.”. Diante dessas análises, conseguimos concluir, por momento, que uma sociedade é formada por instituições que dizem respeito as práticas humanas. Porém, essas práticas pertencem ao campo do abstrato. "Agora, entendidas assim, as instituições são entidades abstratas, por mais que possam estar registradas em escritos ou conservadas em tradições." (BAREMBLITT, 2002).

De acordo Baremblitt (2002) para que uma instituição possa cumprir sua função de regulação da vida humana é preciso que se materializem em grandes ou pequenos conjuntos concretos que lhe deem vida e sentido, e a esses dispositivos ele atribui o nome de "Organizações". 
Contudo, Baremblitt (2002) ainda ressalta que mesmo as "organizações" sendo uma forma de materialização das instituições, essas ainda são compostas por estruturas e ou unidades menores que podem possuir naturezas diversas e que colaboram para a função das instituições. Baremblitt (2002) escreve em seu texto sobre a existência dos agentes, seres humanos que protagonizam formas, estilos de vida e práticas verbais ou não, discursivas ou não discursivas, mas que geram ações, comportamentos e dinamismo a esse elaborado institucional. São essas ações que geram transformações na realidade, segundo o autor.

As sociedades se mostram então, dentro da perspectiva institucional, um grande e elaborado complexo de formações, com uma gama de lógicas setorizadas - Instituição, Organização, Estabelecimento, Equipamento etc. - e que acabam por dar sentido às práticas humanas. Porém, não apenas dão sentido e engendram o comportamento humano, mas que são também transformadas por esses comportamentos, em uma relação recíproca.

Entretanto, ainda nos é necessário entender como são formadas as lógicas advindas das transformações institucionais, conceituadas como "Instituinte", que segundo Baremblitt (2002), são as forças que tendem a fundar, modificar ou transformar essas lógicas institucionais.

Logo, veremos que essa produção de lógicas institucionais denominada Instituinte, gera também um produto, denominado Instituído, que “[...] é o efeito da atividade instituinte." (BAREMBLITT, 2002).

É importante entendermos essas dinâmicas dentro da lógica institucional das sociedades, pois é através desse dinamismo que vão se afirmar as práticas históricas e sociais que trazem sentido à vida em sociedade. Aliás, é dentro desse contexto que conseguiremos manter uma comunicação entre sociedades e as práticas de seus agentes.

Ora, segundo Baremblitt (2002), o instituinte é então aquilo que passa e sinaliza quais práticas são possíveis em uma sociedade e quais não são, dentro de um plano social e histórico. É a força instituinte que é capaz de dar identidade a uma sociedade, como por exemplo, a de consumo. E o instituído é onde são depositados essas práticas e regras, é nele que revigoram as leis e se evidenciam todo um comportamento social.

Agora que conseguimos compreender todo o elaborado de instâncias que constituem uma sociedade e entender a partir da leitura do texto de Baremblitt o que são as instituições e como elas se encarregam de dar sentido, mesmo que abstrato, à lógica social, através de suas organizações, seus agentes e práticas, e entendemos também que uma sociedade é uma rede de instituições que dizem respeito às práticas e as formas de organizações sociais dentro de um contexto histórico. 
Partiremos agora de forma concisa e objetiva em busca de trazer para este artigo uma breve análise dos textos dos autores Deleuze e Foucault, dois exemplos de sociedades: Sociedade Disciplinar e Sociedade de Controle, para, a partir daí, podermos dar início à problematização da Sociedade de Consumo, por meio de outros teóricos.

\section{Disciplina e controle}

Para melhor compreendermos essas sociedades, se faz necessário destacar, e iniciaremos pela Sociedade Disciplinar, o significado que se dava à vida, pois naquela sociedade, era onde se fazia exercer o poder: "Na teoria clássica da soberania, vocês sabem que o direito de vida e de morte era um de seus atributos fundamentais." (FOUCAULT, 2005). Seguindo nessa lógica, o poder soberano se exercia através do corpo, ou melhor: "Em certo sentido, dizer que o soberano tem o direito de vida e de morte significa, no fundo, que ele pode fazer morrer e deixar viver [...]" (FOUCAULT, 2005). Então, na sociedade disciplinar, naquele contexto sócio-histórico, as relações eram submetidas a uma lógica verticalizada, hierarquizada. Diferenciada entre a realidade do soberano e a do súdito.

Quando se vai um pouco mais além e, se vocês quiserem, até o paradoxo, isto quer dizer no fundo que, em relação ao poder, o súdito não é, de pleno direito, nem vivo nem morto. Ele é, do ponto de vista da vida e da morte, neutro, e é simplesmente por causa do soberano que o súdito tem direito de estar vivo ou tem direito, eventualmente, de estar morto. Em todo caso, a vida e a morte dos súditos só se tornam direitos pelo efeito da vontade soberana (FOUCAULT, 2005).

Tornando evidente que a excelência do funcionamento daquela sociedade era a pura soberania. Era o lugar aonde as relações se idealizavam e a forma como elas se tornavam legítimas. Entretanto, essas lógicas funcionais foram se modificando e se transformando ainda no séc. XIX.

E eu creio que, justamente, uma das mais maciças transformações do direito político do século XIX consistiu, não digo exatamente em substituir, mas em completar esse velho direito de soberania - fazer morrer ou deixar viver com outro direito novo, que não vai apagar o primeiro, mas vai penetrá-lo, perpassá-lo, modificá-lo, e que vai ser um direito, ou melhor, um poder exatamente inverso: poder de "fazer" viver e de "deixar" morrer. O direito de soberania é, portanto, o de fazer morrer ou de deixar viver. E depois, este novo direito é que se instala: o direito de fazer viver e de deixar morrer (FOUCAULT, 2005). 
Contudo, assim como nos afirma Foucault (2005), essa transformação não ocorreu de repente. Ela se tornou necessária devido à demanda de uma nova forma de mecanismo institucional, com outras técnicas e tecnologias de poder.

Essa transformação, agora preocupada com o corpo para o trabalho, fazia exercer o poder por meio do que ele chamará de “[...]tecnologia disciplinar do trabalho. Ela se instala no final do século XVII e no decorrer do século XVIII” (FOUCAULT, 2005).

Como afirmara Foucault (2005) essa nova técnica se dirige ao homem vivo, ao homem ser vivo, à vida do homem. Já que na sociedade disciplinar, de maneira contrária, se mantinha pelo direito do soberano de fazer morrer, agora a vida do homem se torna mais importante. Contudo, a partir de agora, um homem visto sob um novo aspecto.

As disciplinas lidavam praticamente com o indivíduo e com seu corpo. Não é exatamente com a sociedade que se lida nessa nova tecnologia de poder (ou, enfim, com o corpo social tal como o definem os juristas); não é tampouco com o indivíduo-corpo. É um novo corpo: corpo múltiplo, corpo com inúmeras cabeças, se não infinito pelo menos necessariamente numerável. É a noção de "população". A biopolítica lida com a população, e a população como problema político, como problema a um só tempo científico e político, como problema biológico e como problema de poder[...] (FOUCAULT, 2005).

A partir daí passamos para um problema não mais do indivíduo apenas, mas de um corpo social, que carece de normas, de regulamentações e de um controle. Um indivíduo em uma sociedade de controle.

Pois aí não se trata, diferentemente das disciplinas, de um treinamento individual realizado por um trabalho no próprio corpo. Não se trata absolutamente de ficar ligado a um corpo individual, como faz a disciplina. Não se trata, por conseguinte, em absoluto, de considerar o indivíduo no nível do detalhe, mas, pelo contrário, mediante mecanismos globais, de agir de tal maneira que se obtenham estados globais de equilíbrio, de regularidade; em resumo, de levar em conta a vida, os processos biológicos do homem-espécie e de assegurar sobre eles não uma disciplina, mas uma regulamentação (FOUCAULT, 2005).

Regulamentação essa que demanda uma disciplina do corpo e um controle do meio social, que cuide de não fazer se perder todo o processo institucional construído até esse momento histórico. Foucault (2005) vai salientar que de uma maneira geral o elemento capaz de controlar e circular entre a ordem disciplinar do corpo e os acontecimentos aleatórios de uma multiplicidade biológica é a "norma". Como norma entendemos o conjunto de regras que regem uma sociedade e o homem na sociedade. 
Deleuze nos mostra que "as sociedades disciplinares têm dois polos: a assinatura que indica o indivíduo, e o número de matrícula que indica sua posição numa massa" (DELEUZE, 1990). Característica essa da disciplina, mas que se faz presente também no controle. As sociedades mudam, mas nem por isso deixam de trazer costumes das anteriores. Nesse momento histórico já não nos encontramos em uma dicotomia Disciplina-Controle ou MassaIndivíduo.

\begin{abstract}
Não se está mais diante do par massa-indivíduo. Os indivíduos tornaram-se "dividuais", divisíveis, e as massas tornaram-se amostras, dados, mercados ou "bancos". É o dinheiro que talvez melhor exprima a distinção entre as duas sociedades, visto que a disciplina sempre se referiu a moedas cunhadas em ouro - que servia de medida padrão -, ao passo que o controle remete a trocas flutuantes, modulações que fazem intervir como cifra uma percentagem de diferentes amostras de moeda (DELEUZE, 1990, p. 2).
\end{abstract}

Nesse sentido, temos aqui um outro problema, o do dinheiro, da concentração e também o da produção. "As conquistas de mercado se fazem por tomada de controle e não mais por formação de disciplinas" (DELEUZE, 2005). Cria-se então o problema do enfraquecimento das instituições, que naquele momento cuidavam apenas do homem e do poder sobre ele, criando dessa forma uma crise das instituições, dando abertura para implementação de um novo regime de dominação (DELEUZE, 1990, p. 4).

Deleuze (1990) termina seu Post-Scriptum relatando o nascimento de uma nova forma de produção de mercado, ocasionada por todo esse processo de crise das instituições, gerada pela mudança também na lógica econômica, comentando sobre o serviço de vendas e o marketing. Agora a sociedade entraria em uma fase de consumo e partiria para uma nova forma institucional cujo "[...] controle é de curto prazo e de rotação rápida, mas também contínuo e ilimitado, ao passo que a disciplina era de longa duração, infinita e descontínua" (DELEUZE, 1990, p. 4).

\title{
Sociedade e consumo
}

Dessa relação entre produção industrial e consumo, Baudrillard (2010, p. 82), percebe a transformação de foco nas produções fabris, que passa a ver no Homem da Sociedade de Consumo uma demanda maior do que a da produção fabril, fazendo do homem objeto da ciência do consumo, pois percebe, na necessidade do agente consumista, uma abertura para a exploração do desejo de compra já existente em todos os agentes "líquido - modernos". Dando assim um novo rumo para a lógica de fabricação deste século, dessa Sociedade de 
Consumo que passa a adotar a produção industrial sempre vinculada à produção das necessidades, em um sistema de necessidades.

O objeto de produção, não deixando de ser o produto, mas sendo ainda mais um sistema de necessidades, não se mantém sozinho sem conseguir antes mudar a demanda da sociedade, construindo uma lógica nas relações e mudando a forma dos significados. "A verdade do consumo reside no facto de ela não ser função de prazer, mas função de produção - e, portanto, tal como acontece com a produção material, função que não é individual, mas imediata e totalmente coletiva" (BAUDRILLARD, 2010, p. 91). Isso ocorre, pois, as relações estão sendo transformadas, estão agora se ressignificando, "O homem moderno passa cada vez menos a vida na produção pelo trabalho e cada vez mais na produção e inovação contínua das próprias necessidades e do bem-estar" (BAUDRILLARD, 2010, p. 94). Nesse sentido, Bauman (2008) nos remete a uma época da história da sociedade que ele denomina de "Sociedade de produtores".

Em uma sociedade de produtores, o "longo prazo" tinha preferência sobre o "curto prazo", e as necessidades do "todo" tinham prioridade em relação às necessidades de suas "partes". As alegrias e as satisfações extraídas dos valores "eternos" e "supraindividuais" eram consideradas superiores aos efêmeros enlevos individuais, enquanto os enlevos da coletividade eram colocados acima da sorte dos poucos, sendo vistos como as únicas satisfações válidas e genuínas em meio à multiplicidade de "prazeres do momento", sedutores mas falsos, inventados, ilusórios e, em última instância, degradantes (BAUMAN, 2008).

Diferente da Sociedade de Consumidores, a Sociedade de Produtores não ansiava por conquistas presentes, mas tinha, no futuro, projetos, frutos da aplicação do seu trabalho: "O "presente" era apenas um meio em relação a um fim, ou seja, para uma felicidade que sempre estava no futuro, sempre "ainda não" (BAUMAN, 2008). E com a mudança de comportamentos sociais, sustentados pela diferença na relação com o consumo, destaca-se ainda que "A sociedade de consumidores talvez seja a única na história humana a prometer felicidade na vida terrena, aqui e agora e a cada 'agora' sucessivo. Em suma, uma felicidade instantânea e perpétua" (BAUMAN, 2008).

Assim como em outras sociedades, existem agora também, toda uma Norma, uma Lógica, que prepara o homem para o consumo. Normas e lógicas que como já sabemos fazem parte de uma instituição, um aparato hierarquizado, para o atendimento das demandas institucional.

Desde antes da produção até a pós-produção, nos alerta Baudrillard (2010, p. 81), a lógica do consumo já está sendo aplicada, produzindo meios de tirar do agente consumidor o 
controle e o poder de decisão e deixando para as empresas esse controle que poderá ser manipulado. $O$ consumidor dessa sociedade não consegue fugir à essa lógica já institucionalizada, sendo ele apenas um meio, um agente nesse complexo relacional que gere as práticas sociais. Afinal, são esses equipamentos que, servindo às instituições e investindo no comportamento de seus agentes, dão sentido às práticas socialmente aceitas.

Por isso, para conseguirmos pensar na sociedade de consumo, temos que tentar primeiramente, compreender que a cultura do consumo, neste estudo, não pretende ser vista de forma perversa, que tende a furtar do sujeito o seu direito à vida, como anteriormente na sociedade disciplinar, poderíamos encontrar, contudo, como uma situação da qual a sociedade se relaciona de maneira sociotemporal.

A própria sociedade de consumidores, diz Bauman (2008), com seus agenciamentos, mecanismos e ferramentas estimulam essas práticas de consumo como uma estratégia existencial que permite uma melhor qualidade de vida em sociedade.

Dificilmente poderia ser de outro jeito, já que o consumismo, em aguda oposição às formas de vida precedentes, associa a felicidade não tanto à satisfação de necessidades (como suas "versões oficiais" tendem a deixar implícito), mas a um volume e uma intensidade de desejos sempre crescentes, o que por sua vez implica o uso imediato e a rápida substituição dos objetos destinados a satisfazê-la (BAUMAN, 2008).

Nesta sociedade de consumo, de acordo com Baudrillard (2010), o indivíduo não alimenta o sistema industrial apenas através dos seus ganhos financeiros, mas toda via e mais ainda, pelo consumo de seus produtos.

Bauman (2008) traz à luz da compreensão que o objetivo crucial do consumo na sociedade de consumidores não é a satisfação das necessidades, mas a mudança da ideia do próprio corpo, o que ele então chamaria de 'comodificação' ou 'recomodificação' do consumidor: elevar a condição dos consumidores à de mercadorias vendáveis.”.

“Comodificação" para Bauman (2008) é a capacidade que o sujeito e ou agente da Sociedade de Consumo possui de se comportar como mercadoria e produto vendível, cujo valor social acompanha a lógica proposta por essa sociedade, uma lógica de agenciamentos para o consumo: O próprio agente consumidor se torna objeto de troca e de venda, se posicionando sempre em evidência para uma valorização de si em relação ao pertencimento, tanto ao campo social quanto ao campo econômico.

"Por outro lado, não existe qualquer outra atividade religiosa, política ou moral, para a qual seja preparado de maneira tão completa, tão científica e tão dispendiosa" (BAUDRILLARD, 2010). Afinal, existe um grande elaborado de organizações, 
estabelecimentos e ferramentas que preparam o sujeito para uma vida de consumo. Dessa forma, temos uma sociedade em que o fim do consumo é o próprio consumo. E os objetos nada mais são que locais de significações mutáveis e substituíveis.

O consumidor na Sociedade de Consumo vive entre a obsolescência e a novidade. "A razão está em que o consumo começa por ser um discurso orquestrado com fim em si mesmo, tendendo a esgotar-se nesta permuta mínima, com suas satisfações e decepções. O objeto de consumo isola" (BAUDRILLARD, 2010).

\section{Agenciamentos e processo de subjetivação: subjetividade}

Interessa-nos, agora, elaborar uma análise sobre o processo de subjetivação, para que possamos melhor compreender os aspectos do desejo dentro da Sociedade de Consumo. Nesse contexto, se fez interessante dialogarmos com dois teóricos, Deleuze e Guattari, por meio dos escritos de Savazzoni.

Quando pensamos “desejo", situados na leitura dos escritos de Deleuze e Guattari, esse pensamento sempre implica o campo Social, Histórico e Político.

Para Deleuze e Guattari importa pensar o desejo em relação aos agenciamentos e, portanto, "fora" de seu suposto objeto. Quando desejamos, não desejamos sozinhos, desejamos sempre conjuntos, em conjuntos, pois o desejo investe sobre todo um campo social, histórico e político (SAVAZZONI, 2012, p. 87).

Para uma melhor compreensão, importa saber que o "agenciamento está conectado a uma perspectiva que concebe desejo enquanto 'fluxo' ou 'intensidade' e de natureza 'produtiva' e 'ativa"” (SAVAZZONI, 2012). O autor continua afirmando que "Entendido na ordem das intensidades (multiplicidades) não há desejo que não corra para um agenciamento, pois o desejo considerado em sua produção imanente, comporta somente fluxos."

É importante entendermos essa dinâmica do desejo e sua relação com os agenciamentos, pois dentro dessa compreensão, "Tudo passa por agenciamentos, somos atravessados, produzidos por eles, e também nos constituímos sobre eles" (SAVAZZONI, 2012).

Logo, quando buscamos compreender a elaboração da subjetividade, deve-se passar pela lógica dos agenciamentos do desejo, em um estado de constantes mudanças e transformações, “[...] entende-se a subjetividade como essencialmente 'industrial' ou 'maquínica', no sentido que ela é constantemente modelada, fabricada e consumida" (SAVAZZONI, 2012). Isso significa dizer que a subjetividade se encontra situada na cultura 
em relação ao ambiente sócio-histórico, e, portanto, ela responde à mecanismos culturais que a moldam a todo o tempo e que não a padronizam, mas transformam, sempre agenciando os fluxos do desejo e criando novas formas de subjetivação.

A questão que se coloca frente à problemática da (produção de) subjetividade encontra fortes ressonâncias com as análises de Deleuze e Guattari acerca dos processos (agenciamentos e dispositivos) maquínicos e enunciativos que compõem o (plano de imanência) campo de experiência do mundo em que será possível a aparição de tipos de "subjetivação" dos quais se produzirá a "forma sujeito" (SAVAZZONI, 2012, p. 67).

Dentro do contexto proposto pelo artigo e relembrando o nosso objeto de pesquisa, devemos então pensar a subjetivação voltada para a cultura de consumo, que responde a uma lógica capitalista de produção de subjetividades. Relação esta que voltaremos a comentar logo mais à frente. Mas, que é valido o seu reforço agora.

Cabe demarcarmos aqui que esta produção de subjetividade que perpassa os indivíduos está sempre em relação com as forças institucionalizantes, e se encarregam de gerir agenciamentos nos fluxos de desejos sempre constantes no corpo social. "Inicialmente, podemos afirmar que 'o' sujeito é um 'ponto (de subjetivação)' resultante de um processo de produção em massa, onde ele é demarcado, modelado, e consumido: são os 'agenciamentos de subjetivação' ( SAVAZZONI, 2012, p. 68).

Entendemos que o sujeito se torna resultado de um processo de produção de massas, de institucionalizações e agenciamentos, cujos fluxos do desejo, por meio de agenciamentos, produzem subjetividades.

Nesse contexto, não podemos pensar o desejo como produto do sujeito, que espera alguma espécie de permissão do campo inconsciente para, então, se fazer evidente nessa relação, como uma instância interior ao sujeito, em que nele se abriga para, assim, criar fluxos como algo que está sempre à procura de um objeto, como se dependesse também de tal objeto para se afirmar.

Savazzoni (2012) reitera "a questão do desejo consiste, portanto, pensá-lo em sua "exterioridade", ou seja, ele não é nem interior a um sujeito, muito menos caminha em direção a um objeto (já que ele é o próprio objeto) [...]”. O desejo é caracterizado então como fluxo e que só pode ser sentido ou capturado por meio de agenciamentos, nos quais o evidencia, porém, não se tornam o seu limiar.

O desejo, como fluxo, está no entre das relações, se evidenciando por meio de agenciamentos. “[...] só se pode agenciar pelo desejo, e só se pode desejar agenciando, sem 
que isso, no entanto implique numa dicotomia entre sujeito 'desejante' e objeto 'desejado"' (SAVAZZONI, 2012).

Não há diferença sob a perspectiva dos fluxos de desejo entre "desejante" e objeto desejado, pois o desejo só pode ser extraído e demonstrado através de agenciamentos. Logo, são os agenciamentos que dão sentido ao desejar, não ao desejo. Pois o desejo é fluxo livre e objeto em si mesmo. Sempre em mudança em um devir contínuo e infinito.

Logo, o desejo nunca está só. É no conjunto das relações entre termos que se produz a realidade de um agenciamento, ou seja, é no meio, e pelo meio, nas conexões, nas misturas de corpos e nas transformações incorpóreas, como também nas territorialidades e nos processos de desterritorialização que se constitui o plano do desejo enquanto devir (SAVAZZONI, 2012, p. 88).

Nesse sentido, o sujeito aqui se faz necessário como integrante de análise para um contexto social de consumo que integra as formas de subjetivação para afirmar suas práticas, pois "devido ao seu alto desenvolvimento tecnológico e também pelo que configura um mercado competitivo e de consumo, a lógica do capitalismo "necessita" de um sujeito, enquanto ponto de "articulação" ou “subjetivação" do capital” (SAVAZZONI, 2012).

Não se trata, portanto, de conceber a subjetividade como recipiente onde as coisas ou representações externas seriam "interiorizadas", mas, pelo contrário, a produção de subjetividade cria modos de subjetivação que são (imanentes) à forma de garantir o funcionamento do sistema (SAVAZZONI, 2012, p. 67-68).

É por meio dessa captura das formas de subjetivação que o sistema capitalista e de consumo mantém viva a sua lógica de funcionamento, resgatando para si os fluxos e agenciamentos e produzindo novos fluxos e agenciamentos também.

No diagnóstico deleuziano, o capitalismo e o desejo estão intrinsecamente ligados num processo de alienação chegando ao ponto de se poder dizer que à força desta aliança se tornaram um só. Isto porque o capitalismo aproveita uma característica do tipo de constituição da personalidade do homem moderno para se instalar como forma única do desejo e da obtenção da satisfação desse desejo fundindo desejo e necessidade num só objecto alucinatório que é repetido/revivido infinitamente no consumo. (ANTUNES, 2014, p. 249).

\section{Da necessidade ao desejo de consumo}

Como afirma Bauman (1999) o consumidor em uma sociedade de consumo se diferencia em demasia dos consumidores de outras sociedades. "Se os nossos ancestrais [...] refletiram se o homem trabalha para viver ou vive para trabalhar, o dilema sobre o qual mais 
se cogita hoje em dia é se é necessário consumir para viver ou se o homem vive para poder consumir" (BAUMAN, 1999, p. 88-89). Isso ocorre porque no atual consumo a lógica não caminha apenas para a aquisição de bens - acumulação de objetos palpáveis, mas, de sensações, Bauman, (1999, p. 91). Isso ocorre como nos afirma Baudrillard (2010) porque o objeto pode ser substituído por outro objeto, quando a intenção da aquisição parte do princípio do desejo na produção dos signos ou a relações sociais

As necessidades na Sociedade de Consumo ganham um novo significado e carregam agora outras intenções. Elas não buscam o objeto em si, sua forma ou utilidade, mas fazem um caminho diferente, pois "as necessidades visam mais os valores que os objetos e a sua satisfação possuem em primeiro lugar o sentido de uma adesão a tais valores" (BAUDRILLARD, 2010, p. 79), dando a entender, assim, como algo que está para além do objeto, para além do próprio ato de consumir. A necessidade do desejo se encontra agora em constante movimento, transpassando objetos, se desdobrando em movimentos líquidos sem que se sinta aprisionada em um final.

Percebe-se, através da releitura de Baudrillard, (2010, p. 90), que o desejo se encontra aqui como insaciável força em continua busca por satisfação, em uma atividade paradoxal em que o objeto em exposição, de compra e ou de venda, não é ainda o objeto final para saciar essa necessidade, mas apenas mais uma mudança de significante. E sobre isso Bauman (2008) traz, em seus argumentos, que a lógica da sociedade de consumo caminha em direção a perpétua não satisfação de seus membros, uma vez que a ânsia pelo caminho da satisfação nunca alcançada é o que mantem a roda do consumo girando a todo o vapor.

Bauman (2008) continua argumentando que essa fenda entre a promessa e o seu cumprimento não é uma falha dessa sociedade, ou um erro de cálculo que precisa ser corrigido, mas sim, uma forma de operação necessária para que a sociedade de consumo continue a prosperar e se manter presente nas relações humanas de consumo. Entende-se então que se trata agora de uma lógica inerente às práticas de vida dos agentes de consumo. Uma prática de uma sociedade que entende que a realização do desejo sempre será substituída pelo anseio a novos desejos, ainda não percebidos: "para os bons consumidores não é a satisfação das necessidades que atormenta a pessoa, mas os tormentos dos desejos ainda não percebidos nem suspeitados que fazem a promessa ser tão tentadora" (BAUMAN, 1999, p. 90).

Bauman (1999) nos afirma que a relação do consumo não se limita a ter que se ser fiel nas escolhas do objeto em exposição, porém, não se consegue fugir da opção de ter que escolher. 
Desse modo, passamos a concordar que o consumo não é mais apenas uma prática cultural, mas trata-se da existência de uma instituição já cristalizada, formadora desta relação consumista. "O consumo surge como conduta activa e colectiva, como coacção e moral, como instituição, compõe todo um sistema de valores, com tudo o que este termo implica enquanto função de integração do grupo de controlo social" (BAUDRILLARD, 2010, p. 95).

Seguindo essa lógica, a Sociedade de consumo se caracteriza não por produzir objetos para o consumo, mas por se preocupar em estar sempre gerando no agente consumidor o desejo de consumo. "O segredo de todo sistema social durável (ou seja, que se auto reproduz com sucesso) é transformar seus "pré-requisitos funcionais" em motivos comportamentais dos atores" (BAUMAN, 2008).

O movimento industrial de fabricação de produtos consumíveis passa, agora, de alguma forma, a focar sua atenção na construção de práticas e comportamentos de consumo.

O produto de competitividade global da fabricante do século deixa de ser o produto, o objeto, a coisa; a mercadoria em si. Os membros dessa sociedade passam a ter esse papel de mercadorias, produtos da fabricação de mercado. "Os membros da sociedade de consumidores são eles próprios mercadorias de consumo e é a qualidade de ser uma mercadoria de consumo que os torna membros autênticos dessa sociedade" (BAUMAN, 2008). São mercadorias pois adotam o lugar de troca e atenção nas negociações do mercado, se colocando assim num papel de agentes ativos do Marketing do consumo.

Não é novidade que atualmente o marketing usa o desejo dos agentes de consumo para que os produtos se vendam, porém, essa é uma aptidão do membro da sociedade de consumo como nos demonstra Bauman (2008), "nessa sociedade, o consumo visto e tratado como vocação é ao mesmo tempo um direito e um dever humano universal que não conhece exceção".

Percebe-se, então, que a própria produção industrial em uma sociedade de consumo se encarrega de produzir o desejo de compra, não sendo mais o consumidor o produto final dessa relação, mas como instituído um resultado de todo esse processo, como nos afirma Baremblitt (2002).

\section{Conclusão}

A sociedade de consumo se caracteriza por ter a dinâmica do consumo como o centro das relações e através dos quais os agenciamentos e estratégias já institucionalizadas se afirmam. Sua forma de organização acontece sobre o viés também do consumo, e até a 
produção industrial foca sua atenção não mais apenas na fabricação de produtos, uma vez que o próprio agente consumidor de suas produções, passa a adquirir novas intenções, novas necessidades.

O consumo nessa sociedade se caracteriza em uma espécie de instituição, na qual dita as normas e as práticas desta sociedade, tendo o consumidor como instituído, ao qual toda essa norma se debruça.

Por meio de agenciamentos do desejo, o consumo consegue se relacionar com as práticas dessa sociedade, que diferente das outras, busca uma satisfação no agora e de forma imediata.

Na questão da produção de subjetividade, podemos destacar as capturas de fluxos de desejo feitas pelos agenciamentos propostos por Deleuze e que trazem sentido à essa lógica de consumo, pois, a todo o momento, estamos envoltos de relações, produções e práticas consumistas em que essas capturas constantes dos desejos através da cultura do consumo potencializam a prática.

Com isso, podemos tentar concluir que a sociedade de consumo cria sujeitos, forma de vida e práticas que não escapam ao consumir, mas não apenas na relação compra e venda, vimos que consumir é, para tal sociedade, o parâmetro para as relações, nas quais o próprio sujeito se coloca à disposição dessa prática. Envolvendo-se e se deixando agenciar.

Interessa-nos em um próximo estudo buscar quais efeitos essa relação de consumo traz para a qualidade de vida de seus agentes, pois já percebemos que ela é capaz de produzir subjetividade e se forma subjetividade também forma afetos, mas quais tipos de afetos?

\section{REFERÊNCIAS}

ANTUNES, M. Â. O. de S. L. C. O desejo maquínico em Gilles Deleuze. 2014. 387 f. Tese (Doutorado em Filosofia) - Universidade de Évora, Évora, 2014.

BAREMBLITT, G. F. Compêndio de análise institucional e outras correntes: teoria e prática. 5. ed. Belo Horizonte, MG: Instituto Felix Guattari, 2002.

BAUDRILLARD, J. A sociedade de consumo. 3. ed. Lisboa: Arte e Comunicação, 2010.

BAUMAN, Z. Globalização: as consequências humanas. Rio de Janeiro: Zahar, 1998.

DELEUZE, G. Post-Scriptum sobre as sociedades de controle. L'Autre Journal, n. 1, 1990.

FOUCAULT, M. Aula de 17 de março de 1976. In: FOUCAULT, M. Em defesa da

sociedade. São Paulo: Martins Fontes, 2005. p. 285-315. 
SAVAZZONI, C. A. Subjetividade e devir à luz da filosofia de Deleuze e Guattari: contribuições para uma psicologia. 2012. 116 f. Dissertação (Mestrado em Psicologia) Universidade de São Paulo, Ribeirão Preto, 2012. Disponível em:

https://www.teses.usp.br/teses/disponiveis/59/59137/tde-04062012-

102459/publico/mestradosavaz.pdf. Acesso em: 15 out. 2019.

\section{Como referenciar este artigo}

SANTOS, R. dos; CRUZ, P. A. D. Sociedade e consumo: uma análise sobre as relações de consumo e o processo de subjetivação na modernidade. Doxa: Rev. Bras. Psico. e Educ., Araraquara, v. 22, n. esp. 1, p. 255-270, out., 2020. e-ISSN: 2594-8385. DOI: https://doi.org/10.30715/doxa.v22iesp.1.14132

Submetido em: $20 / 04 / 2020$

Revisões requeridas: $15 / 06 / 2020$

Aprovado em: 20/08/2020

Publicado em: 30/09/2020 